\title{
Sirtuins and Their Roles in Brain Aging and Neurodegenerative Disorders
}

\author{
Henryk Jęśko ${ }^{1}$ Przemysław Wencel ${ }^{2} \cdot$ Robert P. Strosznajder $^{2} \cdot$ \\ Joanna B. Strosznajder ${ }^{1}$
}

Received: 1 July 2016 / Revised: 21 October 2016 / Accepted: 14 November 2016 / Published online: 24 November 2016

(c) The Author(s) 2016. This article is published with open access at Springerlink.com

\begin{abstract}
Sirtuins (SIRT1-SIRT7) are unique histone deacetylases (HDACs) whose activity depends on $\mathrm{NAD}^{+}$ levels and thus on the cellular metabolic status. SIRTs regulate energy metabolism and mitochondrial function. They orchestrate the stress response and damage repair. Through these functions sirtuins modulate the course of aging and affect neurodegenerative diseases. SIRTSs interact with multiple signaling proteins, transcription factors (TFs) and poly(ADP-ribose) polymerases (PARPs) another class of $\mathrm{NAD}^{+}$-dependent post-translational protein modifiers. The cross-talk between SIRTs TFs and PARPs is a highly promising research target in a number of brain pathologies. This review describes updated results on sirtuins in brain aging/ neurodegeneration. It focuses on SIRT1 but also on the roles of mitochondrial SIRTs (SIRT3, 4, 5) and on SIRT6 and SIRT2 localized in the nucleus and in cytosol, respectively. The involvement of SIRTs in regulation of insulinlike growth factor signaling in the brain during aging and in Alzheimer's disease was also focused. Moreover, we analyze the mechanism(s) and potential significance of interactions between SIRTs and several TFs in the regulation of cell survival and death. A critical view is given on the application of SIRT activators/modulators in therapy of neurodegenerative diseases.
\end{abstract}

Robert P. Strosznajder

rstrosznajder@imdik.pan.pl

1 Department of Cellular Signalling, Mossakowski Medical Research Centre, Polish Academy of Sciences, 5 Pawińskiego st., 02106 Warsaw, Poland

2 Laboratory of Preclinical Research and Environmental Agents, Department of Neurosurgery, Mossakowski Medical Research Centre, Polish Academy of Sciences, 5 Pawińskiego st., 02106 Warsaw, Poland
Keywords Sirtuins · Brain aging · Alzheimer's disease · Parkinson's disease $\cdot$ Neuroprotection · Transcription factors

\section{Introduction}

Sirtuins (SIRT1-SIRT7) belong to the family of histone deacetylases. These enzymes modulate the properties and functions of proteins (e.g. histones, kinases, and transcription factors-TFs) $[1,2]$ by removing acetyl groups posttranslationally attached to their lysine residues by acetyltransferases. Sirtuins are class III HDACs and differ from other classes in that they require $\mathrm{NAD}^{+}$for their activity. This feature couples sirtuin activity to the cellular metabolic status [3], in turn allowing these enzymes to modulate the crucial proteins of the electron transport chain (ETC), stress response, and life/death signaling. Some sirtuins also possess additional enzymatic activities such as mono(ADPribosyl)ation (SIRT3, SIRT4, SIRT6), the ability to remove a wide array of other lysine modifications (e.g. desuccinylation and demalonylation-SIRT5; decrotonylationSIRT1-3), and/or lack detectable deacetylation capability (SIRT4) $[1,2]$. Sirtuins are engaged in cross-talk with a wide spectrum of transcription factors, including forkhead box subgroup $\mathrm{O}$ (FOXOs), p53, and NF- $\mathrm{KB}$, and with proteins engaged in DNA repair such as DNA-dependent protein kinase (DNA-PK) [1, 4]. The versatile and ubiquitous family of poly(ADP-ribose) polymerases (PARPs) shares the feature of $\mathrm{NAD}^{+}$-dependence with sirtuins; the two classes of enzymes compete for the substrate and interact in numerous ways, influencing a very broad range of cellular functions [1,4]. Sirtuins display complex cellular localization in the cytoplasm, nucleus, and mitochondria [2]. All sirtuins are present in the brain in a highly regulated, 
spatiotemporal pattern and may influence the course of aging and pathological changes $[4,5]$.

\section{Sirtuins and Their Roles in Mitochondria: Biogenesis, Energy Production, and Survival/ Death Signaling}

The presence of sirtuins (SIRT3, 4, 5) in mitochondria appears to undergo precise regulation. The exact localization of SIRT3 seems to be species-specific; human SIRT3 is a mitochondrial matrix protein, but its mouse ortholog resides in the inner membrane [6, 7]. SIRT4 and SIRT-5 are also present in the mitochondrial matrix. Human SIRT5 has an additional membrane insertion sequence; its mitochondrial presence depends on the isoform [8]. Mitochondrial localization of sirtuins is mutually interdependent. It is proposed that SIRT3 is present in mitochondria only when the expression of SIRT5 is low [9]. This scattered evidence suggests the possibility of a complex network of regulation for the level and localization of various sirtuins. The results published thus far point to the involvement of sirtuins in the regulation of mitochondrial turnover, fusion and fission, and of mitochondrial cell death signaling. Sirtuins also influence mitochondrial respiratory machinery and ROS production in multiple tissues (Fig. 1). Importantly, the significance of mitochondrial regulation for CNS homeostasis extends well beyond brain neurons, as they are extremely sensitive to the effects of metabolic deregulation in the periphery (with the arginine/urea metabolism being an example of a sirtuin-dependent pathway strongly linked to neurodegenerative conditions). SIRT3 can also enhance via $\mathrm{FOXO} 3$ the expression of antioxidant enzymes including the mitochondrial manganese superoxide dismutase (Mn-SOD), peroxiredoxins, or thioredoxin $2[10,11]$.

SIRT1, mainly a nuclear enzyme, can be also present in mitochondria [12]. Moreover, it has been shown to be engaged in mitochondrial biogenesis [13-15]; reviewed in $[12,16]$. Exercise training increases SIRT1 mRNA level and the amount of mtDNA indicating intensified mitogenesis in most brain regions, with potential cognitive significance [15]. SIRT1 seems to exert this beneficial influence via peroxisome proliferator-activated receptor $\gamma$ co-activator- $1 \alpha$ (PGC-1 $\alpha)$ [17]. PGC- $1 \alpha$ is a crucial regulator of mitochondrial biogenesis and energy metabolism [18, 19]. PGC- $1 \alpha$ is also engaged in antioxidant defense, for example via regulation of Mn-SOD and glutathione peroxidase [20]. Impaired PGC-1 $\alpha$ function may contribute to the pathogenesis of neurodegenerative diseases such as Alzheimer's and Parkinson's (AD and PD, respectively), Huntington's disease, or ischemic damage [21-24]. SIRT3 is also involved in the regulation of mitochondrial biogenesis in a manner mediated by its target FOXO3 and Parkin. SIRT3
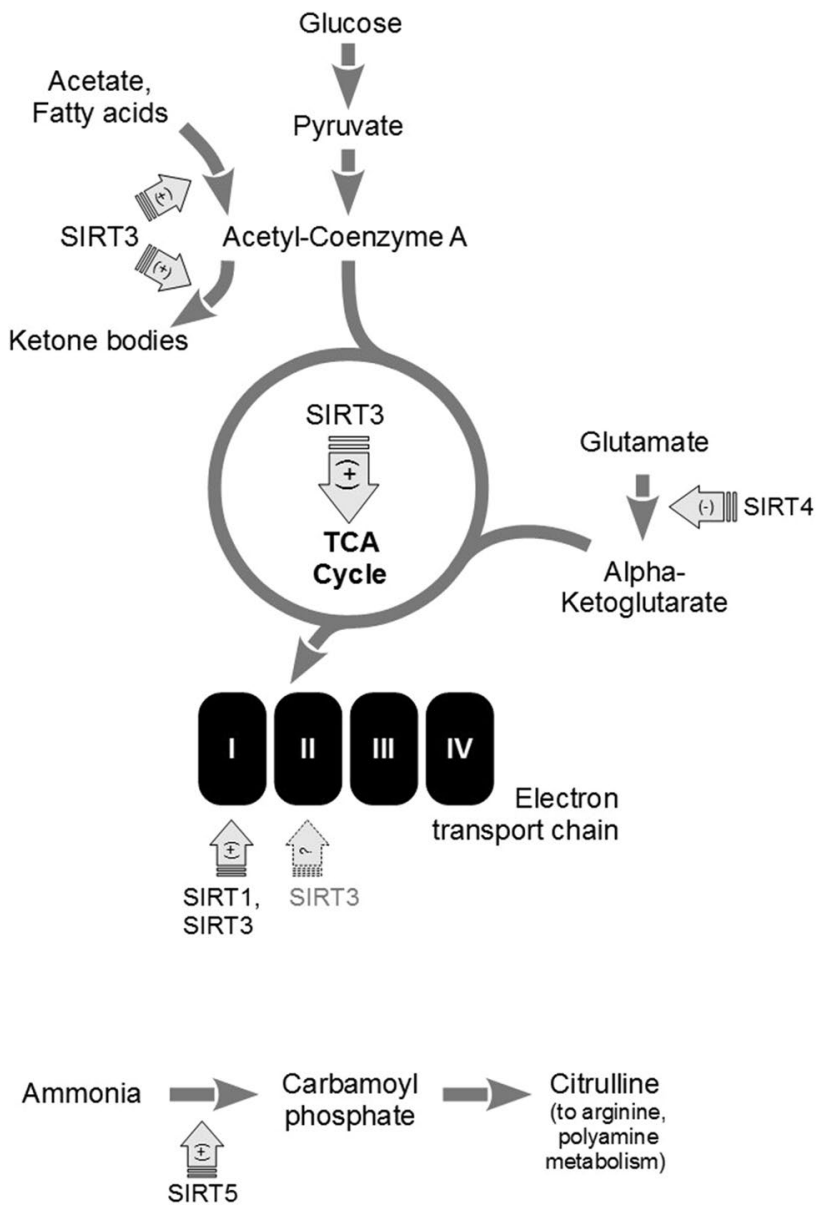

Fig. 1 Mitochondrial targets of sirtuin signalling. Depending on the organ and cell type, sirtuins may affect multiple stages of glucosebased energy metabolism, the production of ketone bodies, glutamate usage, or arginine, citrulline, and polyamine biosynthesis. While numerous metabolites have direct roles in the CNS, others not produced locally, may dramatically impact brain health (as in the case of e.g. urea cycle, which is typically incomplete in the central neurons, but its deregulation in peripheral tissues leads to neurodegeneration in the CNS). According to [40], modified

activates FOXO3a and its target PTEN-induced kinase-1 (PINK-1), a protein known to modulate the cellular redox status and mitochondrial function. PINK-1 in turn enhances Parkin activity, potentiating the fusion of mitochondria and mitophagy [25]. SIRT3 overexpression has led to a significant increase in cellular mtDNA content, while shRNA against SIRT3 has reduced the PGC- $1 \alpha$-mediated rise of mtDNA [26].

The influence of sirtuins on the energy metabolism may also come from their direct interactions with the respiratory machinery (Fig. 1). SIRT3 regulates pyruvate dehydrogenase that is acetylated by the acetyl-CoA acetyltransferase 1 (ACAT1); acetylation/deacetylation status of the dehydrogenase is important for the regulation of glycolysis in cancer cells [27]. Moreover, SIRT3 
deacetylates and stimulates isocitrate dehydrogenase 2, an enzyme of the tricarboxylic acid cycle [28]. Complex I constituent, NADH dehydrogenase $1 \alpha$ subcomplex subunit 9 is deacetylated and activated by SIRT3 [29]. SIRT1 has been shown to enhance the function of complex I in insulin-resistant cells, possibly via SIRT3. Overexpression of SIRT1 attenuated high-fat diet-induced insulin resistance in the skeletal muscle, and restored the levels of SIRT3, mitochondrial antioxidant enzymes and DNA [30]. The part of complex II, succinate dehydrogenase subunit A is also suggested as a SIRT3 substrate [31]. Thus, sirtuins appear to influence several stages of energy metabolism. SIRT4 generally falls in the same scenario. Loss of its expression in several cell types (hepatocytes, muscle) leads to lower ATP production. SIRT4 has been implicated in the regulation of mitochondrial uncoupling. It is also involved in signaling to the nucleus via AMPK, PGC $1 \alpha$ and acetyl-CoA carboxylase, which adjusts mitochondrial ATP production to the energetic demands of the cell [32]. SIRT5, too, has been found to be linked to AMPK, PGC1 $\alpha$ and mitochondrial ATP generation [33].

Mitochondrial sirtuins are involved in the usage of alternative energy sources. The change of energetic substrates is accomplished in hepatocytes by SIRT3 through deacetylation of acyl-CoA dehydrogenases, glutamate dehydrogenase, and the mitochondrial acetyl-CoA synthetase [3436]. These activities allow sustained energy production in the conditions of disturbed supply of the basal substrates. SIRT4 has been found to shift the balance in lipid usage from fatty acid oxidation towards lipid anabolism, by inhibiting malonyl-CoA decarboxylase [37]. Mitochondrial lipid metabolism can be also affected by SIRT5 via its desuccinylase activity directed towards liver mitochondrial proteins engaged in $\beta$-oxidation and ketogenesis [38]. SIRT5 might also influence other aspects of mitochondrial energy production such as the tricarboxylic acid cycle [39].

Besides the ATP generation, SIRT5 regulates the detoxication of ammonia. Through deacetylation, SIRT5 activates the carbamoyl phosphate synthase 1, intensifying the conversion of ammonia into carbamyl phosphate and then citrulline, which is metabolized in the urea cycle (Fig. 1; [40]).

Sirtuins exert their influence on the antioxidative defenses in mitochondria. While PGC- $1 \alpha$ is induced by SIRT1 in rat hippocampus [41], Kong et al. [26] have shown that SIRT3 is an important mediator of the PGC- $1 \alpha-$ dependent induction of SOD2 and glutathione peroxidase-1 (in skeletal muscle cells). A number of articles confirmed the role of SIRT3 in the positive regulation of the level and activity of MnSOD in various tissues [42-44]. SIRT3 also plays a role in the mitochondrial unfolded protein response, which is activated to cope with oxidatively damaged proteins [45].
Sirtuins have been shown to be involved in the regulation of mitochondrial membrane permeability. In cardiac muscle, SIRT3 deacetylates mitochondrial protein cyclophilin $\mathrm{D}$, which is a regulatory component of the permeability transition pore (mPTP) [46]. SIRT5 deacetylates cytochrome c in vitro [47]. However, the outcome of these phenomena is unclear.

\section{Sirtuins in Aging}

The emerging involvement of sirtuins and their targets in the longevity effects of caloric restriction (CR) may be an excellent recapitulation of their roles in the organism's struggle to control and counter stress and macromolecular damage [48]. Sirtuins are bi-directionally linked to the signaling pathways of insulin and insulin-like growth factor-I (IGF-I), collectively termed IIS (insulin/IGF signaling). IGF-I increases SIRT1 expression via JNK1 (c-Jun N-terminal kinase 1 [49]). In turn, SIRT1 and SIRT2 restore the activity of the IGF/insulin receptor target Akt, and SIRT1 supports the IIS signal by deacetylation of insulin receptor substrate 2 (IRS-2). However, SIRT1 and SIRT6 could also suppress the expression of IGF, its receptor, and IISdependent genes in some circumstances [49]. IIS plays highly regulated, important roles in the CNS. IGF-I synthesis declines in old organisms, weakening IGF's trophic action and most probably causing a significant proportion of observed age-related disturbances in brain function [50-52].

Despite the generally trophic role of IGF-I the IIS pathway turns out to be a crucial element of longevity-inhibiting signaling [53]. In invertebrate models of aging, IISdependent suppression of FOXO ortholog (DAF-16) is relieved in conditions of stress such as oxidative damage, starvation, or CR. This de-repression leads to the activation of DAF-16/FOXO-responsive genes, enhancing the resistance to broad range of stress conditions [54-57].

Data obtained in vertebrates also suggest the involvement of IIS in the modulation of stress resistance and, possibly, longevity [53, 58-60]. The effect was dependent on neuronal action of IIS [61, 62]. However, the matter is still not fully settled suggesting that the much higher complexity and redundancy of IIS in mammals requires far more indepth analysis [63, 64].Significant side-effects of reduced IIS also complicate the matters [65-67].

Sirtuins appear to be involved in the longevity-modulating role of IIS; the impact of SIRT1 on long-term survival occurs again through signaling events in specific regions of the CNS [68]. SIRT1 also appears to be involved in the role of IIS in the CR, but sirtuins might also affect the calorie intake itself-again, through the influence on FOXO [54, 69]. A drop in hippocampal SIRT1 level or activity (Fig. 2) 
HIPPOCAMPUS

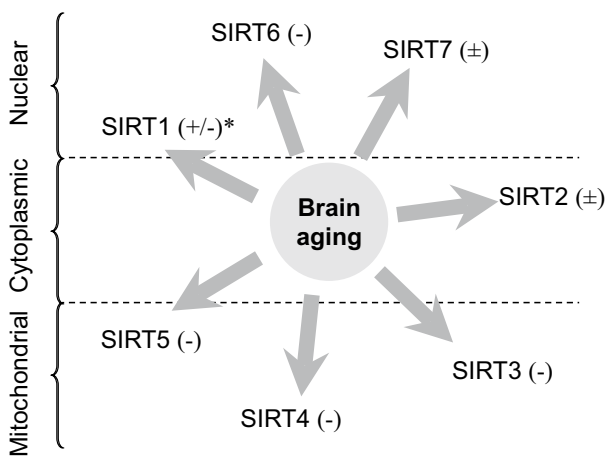

Fig. 2 Changes in the protein levels of various sirtuins in the aged rat brain. The influence of physiological brain aging on the protein levels of various sirtuins in the rodent model. 24 months old rats are compared to adults ( 3 months old). Predominant cellular localizations of

has been noted in the aged rat brain, although the results are inconsistent with some works showing reduced activity despite elevated protein [70, 71].

The expression of SIRT3-SIRT7 undergoes changes in the aging brain in a region-specific manner (Fig. 2; [71, 72]). Single-nucleotide polymorphisms in SIRT3, SIRT5 and SIRT6 genes have been noted to correlate with human lifespan [73].

The potential role for SIRT2 in aging is suggested by the association found between human longevity and a polymorphism in the probable regulatory elements of its gene [74]. Isoform-/region-specific increase of brain SIRT2 content has been observed during aging in mice and rats $[71,75]$. Deacetylation by SIRT2 of the life-span modulating cell cycle checkpoint kinase BubR1 has been shown to preserve its cellular levels while loss of BubR1 is observed in aging muscle due to $\mathrm{NAD}^{+}$decline $[76,77]$. This makes SIRT2 a good candidate for another longevity modulator although it does not seem to be the sole BubR1 regulating factor [78].

SIRT3 single nucleotide polymorphism also seems to associate with human longevity [79, 80], although the data still needs further elaboration [81]. SIRT3 reacts to nutritional status and has been shown to mediate some of the beneficial effects of CR, including many of the CRinduced transcriptional changes in numerous tissues [28, $82,83]$. SIRT3 is increasingly viewed as a modulator of metabolic adaptation to caloric restriction, making it a promising target [84]. Its protein expression changes in a number of mouse peripheral organs during aging, including mouse hematopoietic stem cells where its decrease limits their regenerative potential $[85,86]$. Intense oxidative stress reduces SIRT3 in human mesenchymal stromal/stem cells, which renders them more vulnerable as SIRT3 supports the activity of the catalase-SOD ensemble [87, 88].
CEREBRAL CORTEX

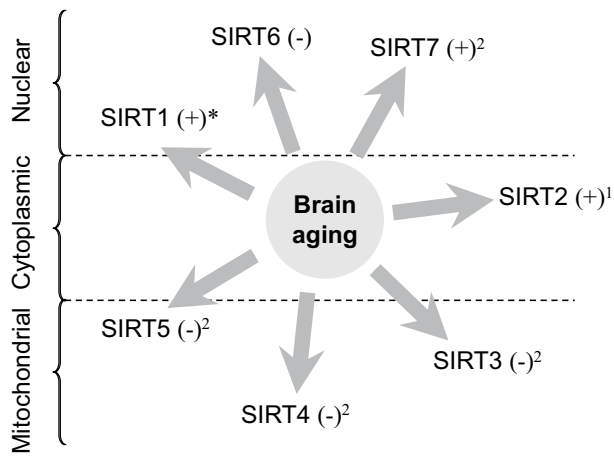

sirtuin proteins are marked in hippocampus and cerebral cortex. ${ }^{ \pm} \mathrm{No}$ change. *Increased protein but lower activity [71]. ${ }^{1}$ Change observed only in the occipital but not frontal or temporal lobes of the cerebral cortex. ${ }^{2}$ Only in frontal but not occipital or temporal lobe

Disturbances in the SIRT3 role as an important free radical defense supporter also appear to contribute to aging of the central auditory system [89]. Moreover, the repertoire of SIRT3 interacting partners suggest further aspects of its role in longevity. Deacetylation by SIRT3 supports the stability and activity of 8-oxoguanine-DNA glycosylase-1 (OGG1), a base excision DNA repair enzyme. This protects mtDNA against accumulation of the mutagenic damage product 8-oxoguanine [90]. SIRT3 also deacetylates DNA repair regulator Ku70 [91]. In addition, SIRT3 binds the heat shock protein HSP70 and causes its increased nuclear presence [92]. These interactions are potentially linked to the mechanisms of age-related neurodegeneration.

Corresponding with SIRT6 role in glucose metabolism and IGF-I homeostasis, results have been obtained suggesting its involvement in CR [93, 94]. Animal models provide somewhat conflicting results on SIRT6 levels during aging [95-97]; some of the age dependency may be explained by the regulatory loop that links SIRT6 with the age-modulated microRNA miR-766 [98]. The potential engagement of SIRT6 disturbances in the aging process is otherwise among the best documented. Suppression of SIRT6 protein levels mediates premature senescence-like phenotype in cells under $\mathrm{H}_{2} \mathrm{O}_{2}$-induced oxidative stress [99]. Premature cell senescence in Hutchinson-Gilford progeria syndrome (HGPS) and chronic obstructive pulmonary disease is linked with lower SIRT6 expression; its restoration remedies a number of senescence-linked traits, in the latter case through modulation of IIS-mTor signaling [100, 101]. The restoration of falling SIRT6 levels also rescues the diminished efficiency of DNA base excision repair in human foreskin fibroblasts from aged donors [102]. Likewise, in the aged brain diminished SIRT6 binding could lead to genomic instability [103]. In turn, some 
peripheral tissues display an age-related rise of SIRT6; its inhibition by physical exercise improved oxidative damage resistance in muscle [96]. SIRT6 ${ }^{-1-}$ mice develop (possibly IGF-I-linked) progeroid-like phenotype, while SIRT6 overexpression supports male longevity in mice which is accompanied by a reduction in serum IGF-I, dramatic increase in the expression of IGF-binding protein-1 mRNA, and changed phosphorylation levels of Akt and FOXO1 [104, 105]. Moreover, SIRT6 binds c-Jun and inhibits its IGF-dependent transcriptional activity [106]. Analysis of SIRT6 interactions (PARP-1, DNA-PK catalytic subunit, other DNA repair proteins, histones) also supports its role in aging, probably through the regulation of chromatin assembly state to facilitate DNA repair in a way somewhat reminiscent of the role of its partner PARP-1 [107]. SIRT6 localizes early to double-strand DNA breaks and is needed for their efficient removal via both pathways: homologous recombination (HR) and non-homologous end-joining (NHEJ) [108, 109]. The mentioned drop in SIRT6 expression during cellular senescence is accompanied by HR deficiency and SIRT6 overexpression largely rescued this phenotype [110]. Cells deficient in SIRT6 enzymatic activity display defects in base excision DNA repair, increased sensitivity to ionizing radiation (but not UV) and multiple chromosomal aberrations though the results clearly need further elucidation [104]. The links between SIRT6, DNA repair, and aging also extend to telomere maintenance. SIRT6 localizes to telomeric chromatin and facilitates the binding of Werner syndrome (WS) protein (WRN) there. WRN is a DNA helicase crucial for genome stability, mutated in the WS. SIRT6 deficiency leads to replicative senescence and telomere dysfunction resembling the pathology seen in WS [111].

The engagement of SIRT6 in the mitigation of aging and oxidative stress also occurs through its interactions with several crucial pathways of transcriptional regulation. SIRT6 has been found to support the transactivation of anti-oxidant genes by nuclear factor erythroid 2-related factor 2 (NRF-2). SIRT-6 deficiency has led to oxidative stress and accelerated decay of human mesenchymal stem cells [112]. NF-кB, another SIRT6 partner, potentially belongs to the crucial modulators of age-related phenotypes [113]. The interaction of SIRT6 with NF-kB subunit RelA recruits SIRT6 to NF-kB target sequences and allows it to repress promoter activities; many of these belong to a group of genes that show increased expression with age $[113,114]$. Experimental SIRT6 deficiency led to hyperacetylation of histones bound to NF- $\mathrm{KB}$ target promoters. This increased the activity of these promoters, augmenting $\mathrm{NF}-\kappa \mathrm{B}$-dependent cellular senescence. This role of NF- $\kappa \mathrm{B}$ has been confirmed in vivo [114]. Hypoxia-inducible factor (HIF) transcription factors are another family of SIRT6 (and SIRT1) interaction partners. The vast significance of
HIFs for the regulation of oxygen + glucose/lactate metabolism suggests their engagement of in the course of aging. In invertebrates HIF-related modulation of the lifespan has been shown, though conflicting views exist whether the pathway is separate from CR- and IGF-dependent longevity modulation $[115,116]$. The above mentioned data and the shortened lifespan of SIRT6-deficient rodents (accompanied by disturbed glucose metabolism) [117] suggest that SIRT-HIF cross-talk might potentially be also engaged in vertebrate longevity. It is known that SIRT1 can inhibit HIF1 and activate HIF2, and that SIRT6 may be a corepressor for HIF-1 $\alpha$ [117-119]. HIF transactivation targets include genes with known neuroprotective influence, although their role in neurodegeneration is still ambiguous $[120,121]$.

Sirt7 has been recently noted to support the regenerative potential hematopoietic stem cells via regulation of mitochondrial stress signaling [122]. Its numerous interactions with enzymes of nucleic acid metabolism strengthen the possible association with life-long maintenance, necessitating further research in the topic [107].

The signaling targets of sirtuin-regulated FOXOs with potential anti-aging significance are still rather unclear; candidates include thioredoxin-interacting protein (Txnip), which is repressed by FOXO1a [123]. Txnip1 suppresses the stress response, correlates negatively with longevity and is viewed as a SIRT1 antagonist [124, 125]. FOXOs also target microRNAs that might modulate stress resistance and long-lived dormant invertebrate developmental states [126]. Several other TFs have been suggested as mediators of the pro-longevity SIRT1 action, but their significance needs further elucidation [127].

\section{Sirtuins in Neurodegeneration and Neuroprotection}

\section{Sirtuins in AD}

A number of works have shown the potential role of sirtuins in AD (Fig. 3) and other neurodegenerative disorders. The reduction of SIRT1 and SIRT3 mRNA/protein levels observed in $\mathrm{AD}$ brain correlates with the stage/duration of the disease $[128,129]$, and can be mimcked in vitro by the influence of $A \beta_{25-35}$ on SIRT1 [130]. In turn, up-regulation of SIRT3 mRNA that followed the spatial and temporal profiles of $A \beta$ accumulation has been shown in mice, and higher SIRT3 mRNA was observed in the temporal cortex of AD cases (Braak tangle stage III-VI, average age $82.5 \pm 2.3$ ) [131]. SIRT5 is induced in activated microglia of $\mathrm{AD}$ brains [129]. In vitro $\mathrm{A} \beta_{1-42}$ treatment also led to increased SIRT-3, -4, and -5 [132]. However, overexpression of APP and presenilin 1 has led to reduction in SIRT3 


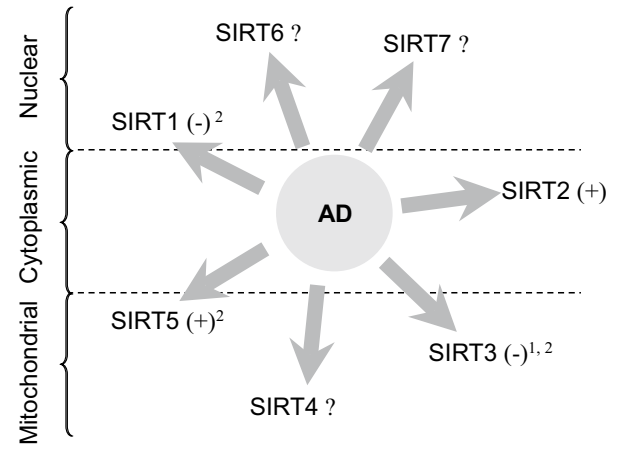

Fig. 3 Changes in the levels of various sirtuins in the course of AD. The influence of $\mathrm{AD}$ pathology on the expression levels of various sirtuins in the human brain. Predominant cellular localizations of sirtuin proteins are marked. ${ }^{ \pm}$No change. ${ }^{1}$ Increased mRNA expression observed in the temporal cortex [131]. ${ }^{2}$ Negative (SIRT1, SIRT3) and positive correlation (SIRT5) of immunoreactivity in the hippocampus with Braak neuropathology staging [129]

mRNA and protein in a mouse model, suggesting more complex relations [133].

It has been reported that SIRT1 shifts the balance between amyloidogenic and non-amyloidogenic processing of APP in vitro and in transgenic mouse models [134]. SIRT1 up-regulates the $\alpha$-secretase ADAM10, and through inhibition of NF- $\mathrm{KB}$ down-regulates the expression of the $\beta$-secretase $\beta$-site A $\beta$ PP-cleaving enzyme 1 (BACE1) (Fig. 4; [135-141]). Moreover, A $\beta$ degradation via autophagy may also be dependent on SIRT1 [142]. Thus, SIRT1 appears to reduce the levels of $A \beta$, oxidative stress and the resulting neuronal loss [139]. Activation or overexpression of SIRT1 is also reported to interfere with A $\beta$ toxicity mediated by microglia through its ability to inhibit NF-kB signaling [143, 144, 148]. SIRT1 might also protect against synapse loss, a more subtle and earlier effect of $A \beta$ pathology [139]. In turn, small-molecule SIRT2 inhibitors 3-(1-azepanylsulfonyl)- $N$-(3-bromphenyl) benzamide (AK7) and 2-cyano-3-[5-(2,5-dichlorophenyl)-2-furanyl]- $N-5$ quinolinyl-2-propenamide (AGK2) have shifted the balance between $\alpha$ - and $\beta$-secretase reducing the $A \beta$ load and led to cognitive improvement in two transgenic mouse models [145]. AGK-2 also reduced glial activation by $\mathrm{A} \beta_{1-42}$ [144]. Thus, SIRT1 and SIRT2 seem to influence the APP cleavage in approximately opposing ways.

Less data is available for other sirtuins. It has been found that short-term treatment with extracellular $\mathrm{A} \beta_{1-42}$ oligomers enhanced the expression of SIRT4 gene but prolonged treatment affected all three mitochondrial isoforms (SIRT3 to SIRT5), suggesting that links between APP/A $\beta$ and SIRTs might be more complex, possibly reciprocal [132].

Intracellular accumulation of pathologically modified microtubule associated protein tau may be another highly promising target in AD research and therapy [146]. Sirtuins

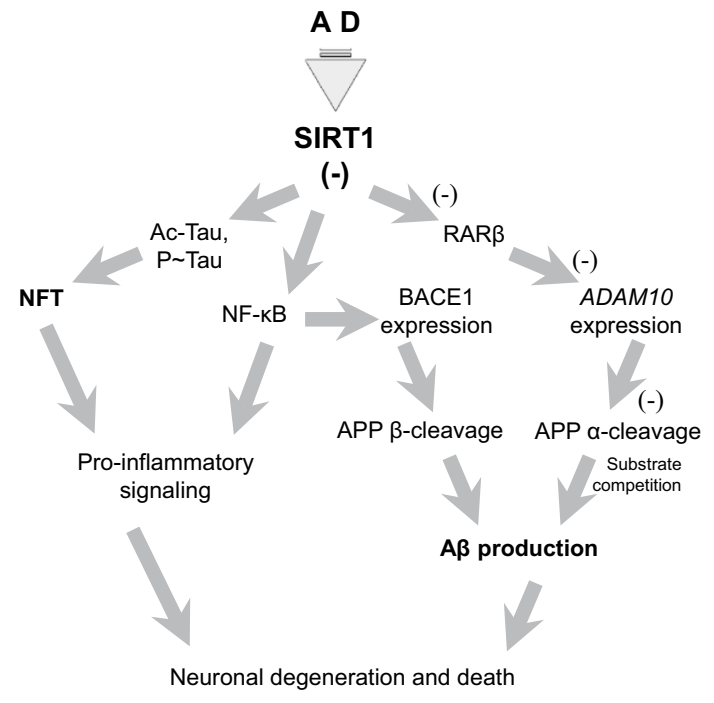

Fig. 4 The significance of SIRT1 in Alzheimer's disease. SIRT1 modulates multiple pathways that adjust the metabolism of $A \beta$ to keep its levels within physiological limits. The sequence of events occurring in AD reduces SIRT1-dependent effects: tau deacetylation, inhibition of the NF- $\kappa$ B pathway, and the $\alpha$-cleavage of APP, leading to elevaed $A \beta$ and to intensified pro-inflammatory signaling

mediate the leptin-dependent inhibition of tau phosphorylation [147]. SIRT1also removes acetyl groups from tau, thus relieving the p300-mediated inhibition of phospho-tau degradation [148]. Manipulations of sirtuin activity could therefore influence tau, potentially changing the number of neurofibrillary tangles (NFT) [149, 150]. Moreover, SIRT1 and tau share common upstream regulation mechanism, as both are targets of microRNA-132 [151] and of ademosine monophosphate-activated kinase (AMPK, which leads to the inhibition of the crucial tau kinase GSK-3 $\beta$, and modulates SIRT1 signaling in a complex manner) [152-154]. These might contribute to the observed inverse correlation between abnormal tau deposition and SIRT1 mRNA and protein levels in $\mathrm{AD}$ [128].

Besides $A \beta$ and tau, the two crucial elements of molecular AD pathology, sirtuin signaling is able to influence pathways engaged in neuroprotection and brain tissue renewal. The SIRT1/retinoic acid receptor $\beta$ target ADAM10 not only cleaves APP but also induces Notch receptor cleavage [155]. The release of Notch intracellular domain activates the transcription of neurogenesis-related genes, and Notch pathway has been shown to be a necessary element of neurogenesis and differentiation of the newly created cells in response to pathological insults [156, 157]. Moreover, Notch targets include genes crucial for synaptic plasticity, learning and memory, and generation of neurites and synapses [155]. Thus, the protection offered by SIRT1 appears to be multi-tiered and stem both from Notch activation and influences on APP and tau metabolism. 
A neuroprotective role of SIRT1 has been also observed in prion diseases [158]. Somewhat surprisingly, numerous results point to detrimental roles played by SIRT2 in neurodegenerative disorders, and in other pathological conditions. SIRT2 is increased in AD; its knock-out or inhibition reduces the cytoskeletal pathology and improves autophagy [159]. A meta-analysis has found an association between a polymorphism in an intron of SIRT2 gene and AD susceptibility [160].

Sirtuin partners FOXOs and the IIS have vast potential significance for AD and other diseases linked to disturbed somatic maintenance. The significance of brain IGF-I signaling and its targets for neuronal survival and death is still poorly known and appears to be fundamentally different from their peripheral roles [161].

IIS has recently become a focus in the research deciphering metabolic disturbances that co-occur with (and possibly precede) $\mathrm{AD}$, raising some hopes for the search of early, measurable symptoms of developing pathology [162]. IIS can suppress $A \beta$ production [163] and resulting tissue damage [164] although its full role in AD is still unclear [165, 166]. Deeper understanding is necessary as it may become an attractive target in the future treatment of $\mathrm{AD}$ and $\mathrm{PD}$ [167]. However, despite the discrepancies IGF-I replacement therapies have been proposed and tested [161, 168].

FOXOs themselves are capable of extensively modulating protein turnover and oxidative stress, both crucial for A $\beta / A S N$ accumulation and toxicity [169]. FOXOs might also mediate the inhibition of neuroprotective PI3K/Akt signaling by $\mathrm{A} \beta[170]$. These TFs have been thus suggested as potential integrating factors in AD metabolic deregulation [171]. The expression of FOXO1 is altered with increased AD severity [172]. FOXO3a might also mediate the toxic effect of $A \beta$-dependent inhibition of neuroprotective PI3K/Akt signaling [170], and the impact of age on FOXO3 has been suggested as a crucial step changing relatively benign protein aggregates into neurotoxic $\mathrm{A} \beta$ deposits [169]. FOXO3a also modulates toxic aggregation of ASN [173] and is found in Lewy bodies/Lewy neurites [174].

\section{Sirtuins in PD}

The course of PD, another neurodegenerative disorder that impacts the dopaminergic system also is affected by SIRT signaling. SIRT1 displays neuroprotective properties in experimental PD models [175, 176]. It was reported that oxyresveratrol protected dopaminergic SH-SY5Y cells against the toxicity of the Parkinsonian mimetic 6-hydroxydopamine through countering the-down regulation of SIRT1. Resveratrol whose functions include activation of SIRT1 also offered protection in this model, as well as in MPTP-induced mouse Parkinsonism [177, 178]. Moreover, genetic variants that result in reduced SIRT1 expression cooccurred with sporadic PD [179].

SIRT1 might exert its protective effects in PD through several pathways linked to general stress resistance and more specifically to $\alpha$-synuclein (ASN) metabolism. The activation of PGC-1 $\alpha$, a protein considered a central element of oxidative stress resistance, by SIRT1 in response to resveratrol may render MPTP-treated mice less prone to neurodegeneration [180]. The protective effect of resveratrol in a rotenone-induced human neuroblastoma cell model of PD has been largely attributed to its ability to induce autophagic degradation of ASN via SIRT1 [181]. Molecular chaperones may also be valuable targets in protein misfolding-related diseases; Hsp70 has been found to protect against ASN aggregation and toxicity [182, 183]. SIRT1 deacetylated the heat shock factor 1 (HSF1) facilitating prolonged binding to its target sequence in the gene coding for Hsp70. This led to elevated expression of Hsp70 in stress conditions [184] raising the possibility that HSF1 and Hsp70 might indeed mediate the protective effect of SIRT1 as it does for example in an amyotrophic lateral sclerosis model [185].

On the contrary, inhibition of SIRT2 with AK-7 reduces MPTP-induced loss of dopaminergic neurons in a mouse model [186]. SIRT2 inhibition improves neurological and behavioral deficits in a PD model induced by MPTP in old mice [187]. siRNA against SIRT2 or its inhibitor AGK2 block the toxic effect of $\alpha$-synuclein in a Parkinsonian primary midbrain culture model (mutant ASN transfection) and modifies the pattern of $\alpha$-synuclein inclusions in cells transfected with ASN and its interaction partner synphilin 1 [188]. SIRT2 inhibition improves neurological and behavioral deficits in a PD model induced by MPTP in old mice [187].

SIRT2 inhibition also blocked the apoptosis of an oligodendroglial cell line in a model of another ASN-linked disorder, multiple system atrophy [189]. Results in cerebral ischemia are less clear [186, 190]. However, SIRT2 has also been shown to contribute to the pathology of the vascular system and to the effects of oxidative stress in the endothelium, which have immediate impact on brain oxygen supply [191, 192].

\section{Sirtuins in HD}

Huntington's disease (HD) is an autosomal trinucleotide repeat disorder characterized by striatal and cortical neurodegeneration leading to motor and cognitive dysfunction. The CAG (polyglutamine) expansion affects the open reading frame of the HTT gene coding for huntingtin. This leads to pathological deposition of huntingtin protein, and disruption of gene regulation, metabolic, and signaling pathways [193]. Weakened trophic support of neurons and 
the resulting nuclear accumulation of FOXO3a transcription factor might be an important aspect [194]. The role of sirtuins in neuronal survival and the known interactions with huntingtin [195] and FOXOs [1] made them a plausible research target. However, sirtuins' role in HD is somewhat controversial, likely stemming from their wide, pleiotropic spectrum of signaling interactions [193]. Till recently, SIRT1 appeared to protect most species from glutamine repeat toxicity, with the notable exception of the Drosophila model [193]. Mutant huntingtin reduces SIRT1 activity, weakening its positive role in neuronal survival. It is possible that the structural similarity between mutant huntingtin and sirtuin-interacting transcription factors might play a role [193]. SIRT1 binds and activates the promoter of brain-derived neurotrophic factor (BDNF); it can also augment the expression of crucial genes such as superoxide dismutase 2, or mitochondrial biogenesis modulators, and can impact Bax signaling via modulation of its binding to Ku70 [196]. However, evidence for neuroprotective influence of selective SIRT1 inhibition in several HD models including mice has been published in recent years; it has been suggested that this approach might augment the clearance of mutant huntingtin [196, 197]. The neuroprotection achieved by SIRT2 inhibition is much more consistent with the current views on its role [193]. The question of possible therapeutic application of sirtuin modulators appears to be tough and highly selective approaches seem necessary.

\section{Pharmacological Manipulation of Sirtuin Activities for Research and Therapeutic Purposes}

A number of pharmacological agents are used to influence the activity of sirtuins for research purposes [198]. HDAC inhibitors display significant level of class specificity: sirtuin inhibitors usually do not affect class I, II or IV enzymes, although the selectivity between sirtuins is a frequent issue [199, 200]. Novel indole compounds seems to offer good specificity and potency while also offering good bioavailability and cell permeability [196]. A new inhibitor 6-chloro-2,3,4,9-tetrahydro-1 $\mathrm{H}$-carbazole-1-carboxamide (EX-527) has been shown to be potent and selective towards SIRT1 [201]. The inhibitor has been used to investigate the role of this isoform in cell physiology and pathology, for example in the regulation of inflammatory responses [202, 203]. In a work on oxidative mitochondrial damage evoked by hyperglycemia the SIRT1 inhibitor has been compared to the effects of siRNA-mediated SIRT1 knock-down [204]. EX-527 has been entered into clinical trials [196]. AGK2, an inhibitor selective towards SIRT2 has been used in a study to assess the role of this sirtuin in the toxicity of $\alpha$-synuclein, mutant huntingtin, and of SIRT2 in cellular energy metabolism [188, 205, 206]. SIRT2 inhibitor
AK-7 was also able to offer neuroprotection in a mouse HD model [193]. 1,2-dihydro-3H-naphtho[2,1-b]pyran-3one (splitomicin) [200]; reviewed in [207] has been used as a basis for an array of derivatives with preferential action against SIRT2 versus SIRT1 [208]. The specificity of the widely employed polyphenolic inhibitor 2-[(2-hydroxynaphthalen-1-ylmethylene)amino]- $N$-(1-phenethyl)benzamide (sirtinol) [207] has been recently questioned [209]. 3,4',5-trihydroxy-trans-stilbene, 5-[(1E)-2-(4-hydroxyphenyl)ethenyl]-1,3-benzenediol (resveratrol), a polyphenol with still unclear mechanism of action has been used to activate sirtuins, with beneficial effects on metabolic regulation, energy metabolism, and organism survival [17, 210]. However, its lack of specificity makes it highly problematic as a research tool [211]. It influences the expression and activity of nitric oxide synthases, catalase, superoxide dismutase, glutathione metabolism, and apoptotic signaling to name a few; only some of these effects are mediated by sirtuins [212]. Despite its shortcomings resveratrol has entered into clinical trials aimed at sirtuins' role in healthy aging and gender-specific longevity mechanisms, in ADrelated cognitive decline, in muscle function in old age, and in the status of a cytoprotective enzyme heme oxygenase- 1 [213-216]. Polyphenolic activators of sirtuins also include the powerful and pleiotropic curcumin. The clear need for more specific and selective compounds has led to the identification of a number of new activators such as $\mathrm{N}$-(2-(3(piperazin-1-ylmethyl)imidazo[2,1-b]thiazol-6-yl)phenyl) quinoxaline-2-carboxamide (SRT1720), 4-methyl- $N$-[2-[3(morpholinomethyl)imidazo[2,1-b]thiazol-6-yl]phenyl]-2(pyridin-3-yl)thiazole-5-carboxamide (SRT2104), which has already been shown to protect against neurodegeneration and motor impairment in a mouse HD model [217]. However, despite their therapeutic potential revealed in animal studies and despite some clinical trials on the improvement of the peripheral metabolic health, clinical CNS data are currently lacking $[10,218,219]$.

\section{Conclusion}

During the past decade, there has been significant progress in understanding the role of sirtuins in brain aging and in neurodegenerative disorders such as $\mathrm{AD}[1,16]$. Till now relatively little is known about the role of SIRTs in PD or Huntighton's disease [5, 196]. The role of SIRT1 in the regulation of APP metabolism and tau deacetylation/phosphorylation should be stressed [147, 148]. SIRT1 expression and activity may significantly affect the course of AD pathology and may be a promising therapeutic target. Recently, studies focused on mitochondrial SIRTs and their roles in antioxidative defense [2]. In oxidative stress and in brain aging/neurodegeration down-regulation of the nuclear 
SIRT6 may influence DNA repair machinery and probably also telomere maintenance. SIRT6 participates in homologus recombinationation, in non-homologus end-joining, and in base excision DNA repair pathways. It interacts with the transcription factor NF- $\kappa \mathrm{B}$, with PARP and with other proteins engaged in DNA repair; this suggests SIRT6 as another promising target in the regulation of longevity $[73,105]$. Till now controversial findings are published on the role of SIRT2 which might be important for longevity but also seems to take part in $\mathrm{A} \beta$ production, $\alpha$-synuclein toxicity, and neuronal cell death $[74,145,188]$. Insufficient data are available on SIRT4 and SIRT5 in mitochondria; the knowledge on sirtuin interactions in the regulation of cell survival and death in physiology and pathology is also leaving something to be desired. Hopefully, further studies will expand our knowledge about application of sirtuin modulators in the therapy of neurodegenerative diseases.

Acknowledgements Authors' work is supported by National Science Centre Grant 2013/09/B/NZ3/01350.

Open Access This article is distributed under the terms of the Creative Commons Attribution 4.0 International License (http:// creativecommons.org/licenses/by/4.0/), which permits unrestricted use, distribution, and reproduction in any medium, provided you give appropriate credit to the original author(s) and the source, provide a link to the Creative Commons license, and indicate if changes were made.

\section{References}

1. Jęśko H, Strosznajder RP (2016) Sirtuins and their interactions with transcription factors and poly(ADP-ribose) polymerases. Folia Neuropathol 54:212-233

2. Kupis W, Pałyga J, Tomal E, Niewiadomska E (2016) The role of sirtuins in cellular homeostasis. J Physiol Biochem 72:371380. doi:10.1007/s13105-016-0492-6

3. Covington JD, Bajpeyi S (2016) The sirtuins: markers of metabolic health. Mol Nutr Food Res 60:79-91. doi:10.1002/ mnfr.201500340

4. Watroba M, Szukiewicz D (2016) The role of sirtuins in aging and age-related diseases. Adv Med Sci 61:52-62. doi:10.1016/j. advms.2015.09.003

5. Tang BL (2016) Sirtuins as modifiers of Parkinson's disease pathology. J Neurosci Res. doi:10.1002/jnr.23806

6. Schwer B, North BJ, Frye RA et al (2002) The human silent information regulator (Sir)2 homologue hSIRT3 is a mitochondrial nicotinamide adenine dinucleotide-dependent deacetylase. J Cell Biol 158:647-657. doi:10.1083/jcb.200205057

7. Shi T, Wang F, Stieren E, Tong Q (2005) SIRT3, a mitochondrial sirtuin deacetylase, regulates mitochondrial function and thermogenesis in brown adipocytes. J Biol Chem 280:13560 13567. doi:10.1074/jbc.M414670200

8. Matsushita N, Yonashiro R, Ogata Y et al (2011) Distinct regulation of mitochondrial localization and stability of two human Sirt5 isoforms. Genes Cells 16:190-202. doi:10.1111/j.1365-2443.2010.01475.x

9. Nakamura Y, Ogura M, Tanaka D, Inagaki N (2008) Localization of mouse mitochondrial SIRT proteins: shift of SIRT3 to nucleus by co-expression with SIRT5. Biochem Biophys Res Commun 366:174-179. doi:10.1016/j.bbrc.2007.11.122

10. Kida Y, Goligorsky MS (2016) Sirtuins, Cell Senescence, and Vascular Aging. Can J Cardiol 32:634-641. doi:10.1016/j. cjca.2015.11.022

11. Tseng AH-H, Wu L-H, Shieh S-S, Wang DL (2014) SIRT3 interactions with FOXO3 acetylation, phosphorylation and ubiquitinylation mediate endothelial cell responses to hypoxia. Biochem J 464:157-168. doi:10.1042/BJ20140213

12. Tang BL (2016) Sirt1 and the Mitochondria. Mol Cells 39:8795. doi:10.14348/molcells.2016.2318

13. Gomes AP, Duarte FV, Nunes P et al (2012) Berberine protects against high fat diet-induced dysfunction in muscle mitochondria by inducing SIRT1-dependent mitochondrial biogenesis. Biochim Biophys Acta 1822:185-195. doi:10.1016/j. bbadis.2011.10.008

14. Seo D-B, Jeong HW, Lee S-J, Lee S-J (2014) Coumestrol induces mitochondrial biogenesis by activating Sirt1 in cultured skeletal muscle cells. J Agric Food Chem 62:4298-4305. doi:10.1021/jf404882w

15. Steiner JL, Murphy EA, McClellan JL et al (2011) Exercise training increases mitochondrial biogenesis in the brain. J Appl Physiol 111:1066-1071. doi:10.1152/japplphysiol.00343.2011

16. Yuan Y, Cruzat VF, Newsholme P et al (2016) Regulation of SIRT1 in aging: roles in mitochondrial function and biogenesis. Mech Ageing Dev 155:10-21. doi:10.1016/j.mad.2016.02.003

17. Lagouge M, Argmann C, Gerhart-Hines $Z$ et al (2006) Resveratrol improves mitochondrial function and protects against metabolic disease by activating SIRT1 and PGC-1alpha. Cell 127:1109-1122. doi:10.1016/j.cell.2006.11.013

18. Villena JA (2015) New insights into PGC-1 coactivators: redefining their role in the regulation of mitochondrial function and beyond. FEBS J 282:647-672. doi:10.1111/febs.13175

19. Handschin C, Spiegelman BM (2006) Peroxisome proliferatoractivated receptor gamma coactivator 1 coactivators, energy homeostasis, and metabolism. Endocr Rev 27:728-735. doi:10.1210/er.2006-0037

20. St-Pierre J, Drori S, Uldry M et al (2006) Suppression of reactive oxygen species and neurodegeneration by the PGC-1 transcriptional coactivators. Cell 127:397-408. doi:10.1016/j. cell.2006.09.024

21. Sweeney G, Song J (2016) The association between PGC-1 $\alpha$ and Alzheimer's disease. Anat Cell Biol 49:1-6. doi:10.5115/ acb.2016.49.1.1

22. Corona JC, Duchen MR (2015) PPAR $\gamma$ and PGC- $1 \alpha$ as therapeutic targets in Parkinson's. Neurochem Res 40:308-316. doi:10.1007/s11064-014-1377-0

23. Johri A, Chandra A, Beal MF (2013) PGC-1 $\alpha$, mitochondrial dysfunction, and Huntington's disease. Free Radic Biol Med 62:37-46. doi:10.1016/j.freeradbiomed.2013.04.016

24. Chen S-D, Yang D-I, Lin T-K et al (2011) Roles of oxidative stress, apoptosis, PGC- $1 \alpha$ and mitochondrial biogenesis in cerebral ischemia. Int J Mol Sci 12:7199-7215. doi:10.3390/ ijms12107199

25. Das S, Mitrovsky G, Vasanthi HR, Das DK (2014) Antiaging properties of a grape-derived antioxidant are regulated by mitochondrial balance of fusion and fission leading to mitophagy triggered by a signaling network of Sirt1-Sirt3Foxo3-PINK1-PARKIN. Oxid Med Cell Longev 2014:345105. doi: $10.1155 / 2014 / 345105$

26. Kong X, Wang R, Xue Y et al (2010) Sirtuin 3, a new target of PGC-1alpha, plays an important role in the suppression of ROS and mitochondrial biogenesis. PLoS ONE 5:e11707. doi:10.1371/journal.pone.0011707

27. Fan J, Shan C, Kang H-B et al (2014) Tyr phosphorylation of PDP1 toggles recruitment between ACAT1 and SIRT3 
to regulate the pyruvate dehydrogenase complex. Mol Cell 53:534-548. doi:10.1016/j.molcel.2013.12.026

28. Someya S, Yu W, Hallows WC et al (2010) Sirt3 mediates reduction of oxidative damage and prevention of age-related hearing loss under caloric restriction. Cell 143:802-812. doi:10.1016/j.cell.2010.10.002

29. Ahn B-H, Kim H-S, Song S et al (2008) A role for the mitochondrial deacetylase Sirt3 in regulating energy homeostasis. Proc Natl Acad Sci USA 105:14447-14452. doi:10.1073/ pnas.0803790105

30. Zhang H-H, Qin G-J, Li X-L et al (2015) SIRT1 overexpression in skeletal muscle in vivo induces increased insulin sensitivity and enhanced complex I but not complex II-V functions in individual subsarcolemmal and intermyofibrillar mitochondria. J Physiol Biochem 71:177-190. doi:10.1007/ s13105-015-0396-x

31. Finley LWS, Haas W, Desquiret-Dumas V et al (2011) Succinate dehydrogenase is a direct target of sirtuin 3 deacetylase activity. PLoS ONE 6:e23295. doi:10.1371/journal. pone.0023295

32. Ho L, Titus AS, Banerjee KK et al (2013) SIRT4 regulates ATP homeostasis and mediates a retrograde signaling via AMPK. Aging 5:835-849

33. Buler M, Aatsinki S-M, Izzi V et al (2014) SIRT5 is under the control of PGC- $1 \alpha$ and AMPK and is involved in regulation of mitochondrial energy metabolism. FASEB J 28:32253237. doi:10.1096/fj.13-245241

34. Hirschey MD, Shimazu T, Goetzman E et al (2010) SIRT3 regulates mitochondrial fatty-acid oxidation by reversible enzyme deacetylation. Nature 464:121-125. doi:10.1038/ nature 08778

35. Lombard DB, Alt FW, Cheng H-L et al (2007) Mammalian Sir2 homolog SIRT3 regulates global mitochondrial lysine acetylation. Mol Cell Biol 27:8807-8814. doi:10.1128/MCB.01636-07

36. Schwer B, Bunkenborg J, Verdin RO et al (2006) Reversible lysine acetylation controls the activity of the mitochondrial enzyme acetyl-CoA synthetase 2. Proc Natl Acad Sci USA 103:10224-10229. doi:10.1073/pnas.0603968103

37. Laurent G, German NJ, Saha AK et al (2013) SIRT4 coordinates the balance between lipid synthesis and catabolism by repressing malonyl CoA decarboxylase. Mol Cell 50:686-698. doi:10.1016/j.molcel.2013.05.012

38. Rardin MJ, He W, Nishida Y et al (2013) SIRT5 regulates the mitochondrial lysine succinylome and metabolic networks. Cell Metab 18:920-933. doi:10.1016/j.cmet.2013.11.013

39. Park J, Chen Y, Tishkoff DX et al (2013) SIRT5-mediated lysine desuccinylation impacts diverse metabolic pathways. Mol Cell 50:919-930. doi:10.1016/j.molcel.2013.06.001

40. Huang J-Y, Hirschey MD, Shimazu T et al (2010) Mitochondrial sirtuins. Biochim Biophys Acta 1804:1645-1651. doi:10.1016/j.bbapap.2009.12.021

41. Wang S-J, Zhao X-H, Chen W et al (2015) Sirtuin 1 activation enhances the PGC- $1 \alpha /$ mitochondrial antioxidant system pathway in status epilepticus. Mol Med Rep 11:521-526. doi:10.3892/mmr.2014.2724

42. Sundaresan NR, Gupta M, Kim G et al (2009) Sirt3 blocks the cardiac hypertrophic response by augmenting Foxo3a-dependent antioxidant defense mechanisms in mice. J Clin Invest 119:2758-2771. doi:10.1172/JCI39162

43. Tao R, Coleman MC, Pennington JD et al (2010) Sirt3-mediated deacetylation of evolutionarily conserved lysine 122 regulates MnSOD activity in response to stress. Mol Cell 40:893904. doi:10.1016/j.molcel.2010.12.013

44. Qiu X, Brown K, Hirschey MD et al (2010) Calorie restriction reduces oxidative stress by SIRT3-mediated SOD2 activation. Cell Metab 12:662-667. doi:10.1016/j.cmet.2010.11.015
45. Papa L, Germain D (2014) SirT3 regulates the mitochondrial unfolded protein response. Mol Cell Biol 34:699-710. doi:10.1128/MCB.01337-13

46. Hafner AV, Dai J, Gomes AP et al (2010) Regulation of the mPTP by SIRT3-mediated deacetylation of CypD at lysine 166 suppresses age-related cardiac hypertrophy. Aging 2:914-923

47. Schlicker C, Gertz M, Papatheodorou P et al (2008) Substrates and regulation mechanisms for the human mitochondrial sirtuins Sirt3 and Sirt5. J Mol Biol 382:790-801. doi:10.1016/j. jmb.2008.07.048

48. Speakman JR, Mitchell SE (2011) Caloric restriction. Mol Aspects Med 32:159-221. doi:10.1016/j.mam.2011.07.001

49. Ng F, Tang BL (2013) When is Sirt1 activity bad for dying neurons? Front Cell Neurosci 7:186. doi:10.3389/fncel.2013.00186

50. Belfiore A, Frasca F, Pandini G et al (2009) Insulin receptor isoforms and insulin receptor/insulin-like growth factor receptor hybrids in physiology and disease. Endocr Rev 30:586-623. doi:10.1210/er.2008-0047

51. Pardo J, Uriarte M, Cónsole GM et al (2016) Insulin-like growth factor-i gene therapy increases hippocampal neurogenesis, astrocyte branching and improves spatial memory in female aging rats. Eur J Neurosci. doi:10.1111/ejn.13278

52. Ashpole NM, Sanders JE, Hodges EL et al (2015) Growth hormone, insulin-like growth factor-1 and the aging brain. Exp Gerontol 68:76-81. doi:10.1016/j.exger.2014.10.002

53. Holzenberger M, Dupont J, Ducos B et al (2003) IGF-1 receptor regulates lifespan and resistance to oxidative stress in mice. Nature 421:182-187. doi:10.1038/nature01298

54. Lee S-H, Min K-J (2013) Caloric restriction and its mimetics. BMB Rep 46:181-187. doi:10.5483/BMBRep.2013.46.4.033

55. Hyun M, Lee J, Lee K et al (2008) Longevity and resistance to stress correlate with DNA repair capacity in Caenorhabditis elegans. Nucleic Acids Res 36:1380-1389. doi:10.1093/nar/ gkm1161

56. Lithgow GJ, Walker GA (2002) Stress resistance as a determinate of C. elegans lifespan. Mech Ageing Dev 123:765-771

57. Vermeulen CJ, Loeschcke V (2007) Longevity and the stress response in Drosophila. Exp Gerontol 42:153-159. doi:10.1016/j.exger.2006.09.014

58. Bonafè M, Barbieri M, Marchegiani F et al (2003) Polymorphic variants of insulin-like growth factor I (IGF-I) receptor and phosphoinositide 3-kinase genes affect IGF-I plasma levels and human longevity: cues for an evolutionarily conserved mechanism of life span control. J Clin Endocrinol Metab 88:3299-3304

59. Deelen J, Uh H-W, Monajemi R et al (2013) Gene set analysis of GWAS data for human longevity highlights the relevance of the insulin/IGF-1 signaling and telomere maintenance pathways. Age (Dordr) 35:235-249. doi:10.1007/s11357-011-9340-3

60. Suh Y, Atzmon G, Cho M-O et al (2008) Functionally significant insulin-like growth factor I receptor mutations in centenarians. Proc Natl Acad Sci USA 105:3438-3442. doi:10.1073/ pnas.0705467105

61. Taguchi A, Wartschow LM, White MF (2007) Brain IRS2 signaling coordinates life span and nutrient homeostasis. Science 317:369-372. doi:10.1126/science.1142179

62. Kappeler L, De Magalhaes Filho C, Dupont J et al (2008) Brain IGF-1 receptors control mammalian growth and lifespan through a neuroendocrine mechanism. PLoS Biol 6:e254. doi:10.1371/journal.pbio.0060254

63. Selman C, Lingard S, Gems D et al (2008) Comment on "Brain IRS2 signaling coordinates life span and nutrient homeostasis." Science. doi:10.1126/science. 1152366

64. Bokov AF, Garg N, Ikeno Y et al (2011) Does reduced IGF1R signaling in Igf1 $\mathrm{r}^{+/-}$mice alter aging? PLoS ONE 6:e26891. doi:10.1371/journal.pone.0026891 
65. Akanji AO, Suresh CG, Al-Radwan R, Fatania HR (2007) Insulin-like growth factor (IGF)-I, IGF-II and IGF-binding protein (IGFBP)-3 levels in Arab subjects with coronary heart disease. Scand J Clin. Lab Invest 67:553-559. doi:10.1080/00365510601173153

66. Juul A, Scheike T, Davidsen M et al (2002) Low serum insulin-like growth factor I is associated with increased risk of ischemic heart disease: a population-based case-control study. Circulation 106:939-944

67. Yamaguchi H, Komamura K, Choraku M et al (2008) Impact of serum insulin-like growth factor-1 on early prognosis in acute myocardial infarction. Intern Med 47:819-825

68. Satoh A, Brace CS, Rensing N et al (2013) Sirt1 extends life span and delays aging in mice through the regulation of $\mathrm{Nk} 2$ homeobox 1 in the DMH and LH. Cell Metab 18:416-430. doi:10.1016/j.cmet.2013.07.013

69. Sasaki T, Kim H-J, Kobayashi M et al (2010) Induction of hypothalamic Sirt1 leads to cessation of feeding via agoutirelated peptide. Endocrinology 151:2556-2566. doi:10.1210/ en.2009-1319

70. Quintas A, de Solís AJ, Díez-Guerra FJ et al (2012) Ageassociated decrease of SIRT1 expression in rat hippocampus: prevention by late onset caloric restriction. Exp Gerontol 47:198-201. doi:10.1016/j.exger.2011.11.010

71. Braidy N, Poljak A, Grant R et al (2015) Differential expression of sirtuins in the aging rat brain. Front Cell Neurosci 9:167. doi:10.3389/fncel.2015.00167

72. Wong DW, Soga T, Parhar IS (2015) Aging and chronic administration of serotonin-selective reuptake inhibitor citalopram upregulate Sirt4 gene expression in the preoptic area of male mice. Front Genet 6:281. doi:10.3389/fgene.2015.00281

73. TenNapel MJ, Lynch CF, Burns TL et al (2014) SIRT6 minor allele genotype is associated with $>5$-year decrease in lifespan in an aged cohort. PLoS ONE 9:e115616. doi:10.1371/ journal.pone. 0115616

74. Crocco P, Montesanto A, Passarino G, Rose G (2015) Polymorphisms falling within putative miRNA target sites in the 3'UTR region of SIRT2 and DRD2 genes are correlated with human longevity. J Gerontol A Biol Sci Med Sci. doi:10.1093/ gerona/glv058

75. Maxwell MM, Tomkinson EM, Nobles J et al (2011) The Sirtuin 2 microtubule deacetylase is an abundant neuronal protein that accumulates in the aging CNS. Hum Mol Genet 20:3986-3996. doi:10.1093/hmg/ddr326

76. Baker DJ, Dawlaty MM, Wijshake T et al (2013) Increased expression of BubR1 protects against aneuploidy and cancer and extends healthy lifespan. Nat Cell Biol 15:96-102. doi:10.1038/ncb2643

77. North BJ, Rosenberg MA, Jeganathan KB et al (2014) SIRT2 induces the checkpoint kinase BubR1 to increase lifespan. EMBO J 33:1438-1453. doi:10.15252/embj.201386907

78. Cosentino C, Mostoslavsky R (2014) Sirtuin to the rescue: SIRT2 extends life span of BubR1 mice. EMBO J 33:14171419. doi:10.15252/embj.201488983

79. Bellizzi D, Rose G, Cavalcante P et al (2005) A novel VNTR enhancer within the SIRT3 gene, a human homologue of SIR2, is associated with survival at oldest ages. Genomics 85:258-263. doi:10.1016/j.ygeno.2004.11.003

80. Albani D, Ateri E, Mazzuco S et al (2014) Modulation of human longevity by SIRT3 single nucleotide polymorphisms in the prospective study "Treviso Longeva (TRELONG)." Age (Dordr) 36:469-478. doi:10.1007/s11357-013-9559-2

81. Giblin W, Skinner ME, Lombard DB (2014) Sirtuins: guardians of mammalian healthspan. Trends Genet 30:271-286. doi:10.1016/j.tig.2014.04.007
82. Palacios OM, Carmona JJ, Michan S et al (2009) Diet and exercise signals regulate SIRT3 and activate AMPK and PGC-1alpha in skeletal muscle. Aging 1:771-783

83. Barger JL, Anderson RM, Newton MA et al (2015) A conserved transcriptional signature of delayed aging and reduced disease vulnerability is partially mediated by SIRT3. PLoS One. doi:10.1371/journal.pone.0120738

84. Kincaid B, Bossy-Wetzel E (2013) Forever young: SIRT3 a shield against mitochondrial meltdown, aging, and neurodegeneration. Front Aging Neurosci 5:48. doi:10.3389/ fnagi.2013.00048

85. Kwon Y, Kim J, Lee C-Y, Kim H (2015) Expression of SIRT1 and SIRT3 varies according to age in mice. Anat Cell Biol 48:54-61. doi:10.5115/acb.2015.48.1.54

86. Brown K, Xie S, Qiu X et al (2013) SIRT3 reverses agingassociated degeneration. Cell Rep 3:319-327. doi:10.1016/j. celrep.2013.01.005

87. Iwahara T, Bonasio R, Narendra V, Reinberg D (2012) SIRT3 functions in the nucleus in the control of stress-related gene expression. Mol Cell Biol 32:5022-5034. doi:10.1128/ MCB.00822-12

88. Wang X-Q, Shao Y, Ma C-Y et al (2014) Decreased SIRT3 in aged human mesenchymal stromal/stem cells increases cellular susceptibility to oxidative stress. J Cell Mol Med 18:2298-2310. doi:10.1111/jcmm.12395

89. Zeng L, Yang Y, Hu Y et al (2014) Age-related decrease in the mitochondrial sirtuin deacetylase Sirt3 expression associated with ROS accumulation in the auditory cortex of the mimetic aging rat model. PLoS ONE 9:e88019. doi:10.1371/ journal.pone.0088019

90. Cheng Y, Ren X, Gowda ASP et al (2013) Interaction of Sirt3 with OGG1 contributes to repair of mitochondrial DNA and protects from apoptotic cell death under oxidative stress. Cell Death Dis 4:e731. doi:10.1038/cddis.2013.254

91. Sundaresan NR, Samant SA, Pillai VB et al (2008) SIRT3 is a stress-responsive deacetylase in cardiomyocytes that protects cells from stress-mediated cell death by deacetylation of Ku70. Mol Cell Biol 28:6384-6401. doi:10.1128/ MCB.00426-08

92. Law IKM, Liu L, Xu A et al (2009) Identification and characterization of proteins interacting with SIRT1 and SIRT3: implications in the anti-aging and metabolic effects of sirtuins. Proteomics 9:2444-2456. doi:10.1002/pmic.200800738

93. Zhang P, Tu B, Wang H et al (2014) Tumor suppressor p53 cooperates with SIRT6 to regulate gluconeogenesis by promoting FoxO1 nuclear exclusion. Proc Natl Acad Sci USA 111:10684-10689. doi:10.1073/pnas.1411026111

94. Kanfi Y, Shalman R, Peshti V et al (2008) Regulation of SIRT6 protein levels by nutrient availability. FEBS Lett 582:543-548. doi:10.1016/j.febslet.2008.01.019

95. Ghiraldini FG, Crispim ACV, Mello MLS (2013) Effects of hyperglycemia and aging on nuclear sirtuins and DNA damage of mouse hepatocytes. Mol Biol Cell 24:2467-2476. doi:10.1091/mbc.E13-04-0186

96. Koltai E, Szabo Z, Atalay M et al (2010) Exercise alters SIRT1, SIRT6, NAD and NAMPT levels in skeletal muscle of aged rats. Mech Ageing Dev 131:21-28. doi:10.1016/j. $\operatorname{mad} .2009 .11 .002$

97. Ren Y, Shan TZ, Zhu LN et al (2013) Effect of breed on the expression of Sirtuins (Sirt1-7) and antioxidant capacity in porcine brain. Animal 7:1994-1998. doi:10.1017/ S175173111300164X

98. Sharma A, Diecke S, Zhang WY et al (2013) The role of SIRT6 protein in aging and reprogramming of human induced pluripotent stem cells. J Biol Chem 288:18439-18447. doi:10.1074/ jbc.M112.405928 
99. Liu R, Liu H, Ha Y et al (2014) Oxidative stress induces endothelial cell senescence via downregulation of Sirt6. Biomed Res Int. doi:10.1155/2014/902842

100. Endisha H, Merrill-Schools J, Zhao M et al (2015) Restoring SIRT6 expression in Hutchinson-Gilford progeria syndrome cells impedes premature senescence and formation of dysmorphic nuclei. Pathobiology 82:9-20. doi:10.1159/000368856

101. Takasaka N, Araya J, Hara H et al (2014) Autophagy induction by SIRT6 through attenuation of insulin-like growth factor signaling is involved in the regulation of human bronchial epithelial cell senescence. J Immunol 192:958-968. doi:10.4049/jimmunol.1302341

102. Xu Z, Zhang L, Zhang W et al (2015) SIRT6 rescues the age related decline in base excision repair in a PARP1-dependent manner. Cell Cycle 14:269-276. doi:10.4161/15384101.2014. 980641

103. Van Meter M, Kashyap M, Rezazadeh S et al (2014) SIRT6 represses LINE1 retrotransposons by ribosylating KAP1 but this repression fails with stress and age. Nat Commun 5:5011. doi:10.1038/ncomms6011

104. Mostoslavsky R, Chua KF, Lombard DB et al (2006) Genomic instability and aging-like phenotype in the absence of mammalian SIRT6. Cell 124:315-329. doi:10.1016/j. cell.2005.11.044

105. Kanfi Y, Naiman S, Amir G et al (2012) The sirtuin SIRT6 regulates lifespan in male mice. Nature 483:218-221. doi:10.1038/nature10815

106. Sundaresan NR, Vasudevan P, Zhong L et al (2012) The sirtuin SIRT6 blocks IGF-Akt signaling and development of cardiac hypertrophy by targeting c-Jun. Nat Med 18:1643-1650. doi:10.1038/nm.2961

107. Lee N, Kim D-K, Kim E-S et al (2014) Comparative interactomes of SIRT6 and SIRT7: implication of functional links to aging. Proteomics 14:1610-1622. doi:10.1002/ pmic. 201400001

108. Toiber D, Erdel F, Bouazoune K et al (2013) SIRT6 recruits SNF2H to DNA break sites, preventing genomic instability through chromatin remodeling. Mol Cell 51:454-468. doi:10.1016/j.molcel.2013.06.018

109. Mao Z, Hine C, Tian X et al (2011) SIRT6 promotes DNA repair under stress by activating PARP1. Science 332:14431446. doi:10.1126/science. 1202723

110. Mao Z, Tian X, Van Meter M et al (2012) Sirtuin 6 (SIRT6) rescues the decline of homologous recombination repair during replicative senescence. Proc Natl Acad Sci USA 109:1180011805. doi:10.1073/pnas.1200583109

111. Michishita E, McCord RA, Berber E et al (2008) SIRT6 is a histone $\mathrm{H} 3$ lysine 9 deacetylase that modulates telomeric chromatin. Nature 452:492-496. doi:10.1038/nature06736

112. Pan H, Guan D, Liu X et al (2016) SIRT6 safeguards human mesenchymal stem cells from oxidative stress by coactivating NRF2. Cell Res. doi:10.1038/cr.2016.4

113. Adler AS, Sinha S, Kawahara TLA et al (2007) Motif module map reveals enforcement of aging by continual NF-kappaB activity. Genes Dev 21:3244-3257. doi:10.1101/gad.1588507

114. Kawahara TLA, Michishita E, Adler AS et al (2009) SIRT6 links histone $\mathrm{H} 3$ lysine 9 deacetylation to control of NF-кB dependent gene expression and organismal lifespan. Cell 136:62-74. doi:10.1016/j.cell.2008.10.052

115. Chen D, Thomas EL, Kapahi P (2009) HIF-1 modulates dietary restriction-mediated lifespan extension via IRE-1 in Caenorhabditis elegans. PLoS Genet 5:e1000486. doi:10.1371/journal. pgen. 1000486

116. Mehta R, Steinkraus KA, Sutphin GL et al (2009) Proteasomal regulation of the hypoxic response modulates aging in C. elegans. Science 324:1196-1198. doi:10.1126/science.1173507
117. Zhong L, D'Urso A, Toiber D et al (2010) The histone deacetylase Sirt6 regulates glucose homeostasis via Hif1alpha. Cell 140:280-293. doi:10.1016/j.cell.2009.12.041

118. Lim J-H, Lee Y-M, Chun Y-S et al (2010) Sirtuin 1 modulates cellular responses to hypoxia by deacetylating hypoxiainducible factor 1alpha. Mol Cell 38:864-878. doi:10.1016/j molcel.2010.05.023

119. Dioum EM, Chen R, Alexander MS et al (2009) Regulation of hypoxia-inducible factor 2alpha signaling by the stress-responsive deacetylase sirtuin 1 . Science 324:1289-1293. doi:10.1126/ science. 1169956

120. Trollmann R, Gassmann M (2009) The role of hypoxia-inducible transcription factors in the hypoxic neonatal brain. Brain Dev 31:503-509. doi:10.1016/j.braindev.2009.03.007

121. Fan X, Heijnen CJ, van der Kooij MA et al (2009) The role and regulation of hypoxia-inducible factor- $1 \alpha$ expression in brain development and neonatal hypoxic-ischemic brain injury. Brain Res Rev 62:99-108. doi:10.1016/j.brainresrev.2009.09.006

122. Mohrin M, Shin J, Liu Y et al (2015) Stem cell aging. A mitochondrial UPR-mediated metabolic checkpoint regulates hematopoietic stem cell aging. Science 347:1374-1377. doi:10.1126/ science.aaa2361

123. de Candia P, Blekhman R, Chabot AE et al (2008) A combination of genomic approaches reveals the role of FOXO1a in regulating an oxidative stress response pathway. PLoS ONE 3:e1670. doi:10.1371/journal.pone.0001670

124. Dunn LL, Buckle AM, Cooke JP, Ng MKC (2010) The emerging role of the thioredoxin system in angiogenesis. Arterioscler Thromb Vasc Biol 30:2089-2098. doi:10.1161/ ATVBAHA.110.209643

125. Chondrogianni N, de C M Simoes D, Franceschi C, Gonos ES (2004) Cloning of differentially expressed genes in skin fibroblasts from centenarians. Biogerontology 5:401-409. doi:10.1007/s10522-004-3188-1

126. Baugh LR, Sternberg PW (2006) DAF-16/FOXO regulates transcription of cki-1/Cip/Kip and repression of lin-4 during C. elegans L1 arrest. Curr Biol 16:780-785. doi:10.1016/j. cub.2006.03.021

127. Ng F, Wijaya L, Tang BL (2015) SIRT1 in the brain-connections with aging-associated disorders and lifespan. Front Cell Neurosci 9:64. doi:10.3389/fncel.2015.00064

128. Julien C, Tremblay C, Emond V et al (2009) Sirtuin 1 reduction parallels the accumulation of tau in Alzheimer disease. J Neuropathol Exp Neurol 68:48-58. doi:10.1097/ NEN.0b013e3181922348

129. Lutz MI, Milenkovic I, Regelsberger G, Kovacs GG (2014) Distinct patterns of sirtuin expression during progression of Alzheimer's disease. Neuromolecular Med 16:405-414. doi:10.1007/ s12017-014-8288-8

130. Lattanzio F, Carboni L, Carretta D et al (2016) Treatment with the neurotoxic $A \beta(25-35)$ peptide modulates the expression of neuroprotective factors Pin1, Sirtuin 1, and brain-derived neurotrophic factor in SH-SY5Y human neuroblastoma cells. Exp Toxicol Pathol 68:271-276. doi:10.1016/j.etp.2016.02.001

131. Weir HJM, Murray TK, Kehoe PG et al (2012) CNS SIRT3 expression is altered by reactive oxygen species and in Alzheimer's disease. PLoS ONE 7:e48225. doi:10.1371/journal. pone. 0048225

132. Cieślik M, Czapski GA, Strosznajder JB (2015) The molecular mechanism of amyloid $\beta 42$ peptide toxicity: the role of sphingosine kinase-1 and mitochondrial sirtuins. PLoS ONE 10:e0137193. doi:10.1371/journal.pone.0137193

133. Yang W, Zou Y, Zhang M et al (2015) Mitochondrial Sirt3 expression is decreased in APP/PS1 double transgenic mouse model of Alzheimer's disease. Neurochem Res 40:1576-1582. doi:10.1007/s11064-015-1630-1 
134. Qin W, Yang T, Ho L et al (2006) Neuronal SIRT1 activation as a novel mechanism underlying the prevention of Alzheimer disease amyloid neuropathology by calorie restriction. J Biol Chem 281:21745-21754. doi:10.1074/jbc.M602909200

135. Tippmann F, Hundt J, Schneider A et al (2009) Up-regulation of the alpha-secretase ADAM10 by retinoic acid receptors and acitretin. FASEB J 23:1643-1654. doi:10.1096/fj.08-121392

136. Wang J, Fivecoat H, Ho L et al (2010) The role of Sirt1: at the crossroad between promotion of longevity and protection against Alzheimer's disease neuropathology. Biochim Biophys Acta 1804:1690-1694. doi:10.1016/j.bbapap.2009.11.015

137. Lee HR, Shin HK, Park SY et al (2014) Cilostazol suppresses $\beta$-amyloid production by activating a disintegrin and metalloproteinase 10 via the upregulation of SIRT1-coupled retinoic acid receptor- $\beta$. J Neurosci Res 92:1581-1590. doi:10.1002/ jnr.23421

138. Marwarha G, Raza S, Meiers C, Ghribi O (2014) Leptin attenuates BACE1 expression and amyloid- $\beta$ genesis via the activation of SIRT1 signaling pathway. Biochim Biophys Acta 1842:1587-1595. doi:10.1016/j.bbadis.2014.05.015

139. Godoy JA, Zolezzi JM, Braidy N, Inestrosa NC (2014) Role of Sirt1 during the ageing process: relevance to protection of synapses in the brain. Mol Neurobiol 50:744-756. doi:10.1007/ s12035-014-8645-5

140. Guo P, Wang D, Wang X et al (2016) Effect and mechanism of fuzhisan and donepezil on the sirtuin 1 pathway and amyloid precursor protein metabolism in PC12 cells. Mol Med Rep 13:3539-3546. doi: $10.3892 / \mathrm{mmr} .2016 .4957$

141. Gao R, Wang Y, Pan Q et al (2015) Fuzhisan, a chinese herbal medicine, suppresses beta-secretase gene transcription via upregulation of SIRT1 expression in N2a-APP695 cells. Int J Clin Exp Med 8:7231-7240

142. Park SY, Lee HR, Lee WS et al (2016) Cilostazol modulates autophagic degradation of $\beta$-amyloid peptide via SIRT1-coupled LKB1/AMPK $\alpha$ signaling in neuronal cells. PLoS ONE 11:e0160620. doi:10.1371/journal.pone.0160620

143. Chen J, Zhou Y, Mueller-Steiner S et al (2005) SIRT1 protects against microglia-dependent amyloid-beta toxicity through inhibiting NF-kappaB signaling. J Biol Chem 280:4036440374. doi:10.1074/jbc.M509329200

144. Scuderi C, Stecca C, Bronzuoli MR et al (2014) Sirtuin modulators control reactive gliosis in an in vitro model of Alzheimer's disease. Front Pharmacol 5:89. doi:10.3389/fphar.2014.00089

145. Biella G, Fusco F, Nardo E et al (2016) Sirtuin 2 inhibition improves cognitive performance and acts on amyloid- $\beta$ protein precursor processing in two Alzheimer's disease mouse models. J Alzheimers Dis 53:1193-1207. doi:10.3233/JAD-151135

146. Chesser AS, Pritchard SM, Johnson GVW (2013) Tau clearance mechanisms and their possible role in the pathogenesis of Alzheimer disease. Front Neurol 4:122. doi:10.3389/ fneur.2013.00122

147. Greco SJ, Hamzelou A, Johnston JM et al (2011) Leptin boosts cellular metabolism by activating AMPK and the sirtuins to reduce tau phosphorylation and $\beta$-amyloid in neurons. Biochem Biophys Res Commun 414:170-174. doi:10.1016/j. bbrc.2011.09.050

148. Min S-W, Cho S-H, Zhou Y et al (2010) Acetylation of tau inhibits its degradation and contributes to tauopathy. Neuron 67:953-966. doi:10.1016/j.neuron.2010.08.044

149. Du L-L, Xie J-Z, Cheng X-S et al (2014) Activation of sirtuin 1 attenuates cerebral ventricular streptozotocin-induced tau hyperphosphorylation and cognitive injuries in rat hippocampi. Age (Dordr) 36:613-623. doi:10.1007/s11357-013-9592-1

150. Corpas R, Revilla S, Ursulet S et al (2016) SIRT1 overexpression in mouse hippocampus induces cognitive enhancement through proteostatic and neurotrophic mechanisms. Mol Neurobiol. doi:10.1007/s12035-016-0087-9

151. Hernandez-Rapp J, Rainone S, Goupil C et al (2016) microRNA-132/212 deficiency enhances $A \beta$ production and senile plaque deposition in Alzheimer's disease triple transgenic mice. Sci Rep 6:30953. doi:10.1038/srep30953

152. Salminen A, Kaarniranta K (2012) AMP-activated protein kinase (AMPK) controls the aging process via an integrated signaling network. Ageing Res Rev 11:230-241. doi:10.1016/j. arr.2011.12.005

153. Kim H-S, Moon S, Paik J-H et al (2015) Activation of the 5 -AMP-activated protein kinase in the cerebral cortex of young senescence-accelerated P8 mice and association with GSK3 $\beta$ and PP2A-dependent inhibition of p-tau ${ }_{396}$ expression. J Alzheimers Dis 46:249-259. doi:10.3233/JAD-150035

154. Park H, Kam T-I, Kim Y et al (2012) Neuropathogenic role of adenylate kinase-1 in $\mathrm{A} \beta$-mediated tau phosphorylation via AMPK and GSK3 $\beta$. Hum Mol Genet 21:2725-2737. doi:10.1093/hmg/dds 100

155. Costa RM, Drew C, Silva AJ (2005) Notch to remember. Trends Neurosci 28:429-435. doi:10.1016/j.tins.2005.05.003

156. Bonda DJ, Lee H-G, Camins A et al (2011) The sirtuin pathway in ageing and Alzheimer disease: mechanistic and therapeutic considerations. Lancet Neurol 10:275-279. doi:10.1016/ S1474-4422(11)70013-8

157. Xiao M-J, Han Z, Shao B, Jin K (2009) Notch signaling and neurogenesis in normal and stroke brain. Int J Physiol Pathophysiol Pharmacol 1:192-202

158. Seo J-S, Moon M-H, Jeong J-K et al (2012) SIRT1, a histone deacetylase, regulates prion protein-induced neuronal cell death. Neurobiol Aging 33:1110-1120. doi:10.1016/j. neurobiolaging.2010.09.019

159. Silva DF, Esteves AR, Oliveira CR, Cardoso SM (2016) Mitochondrial metabolism power SIRT2-dependent deficient traffic causing Alzheimer's-disease related pathology. Mol Neurobiol. doi:10.1007/s12035-016-9951-x

160. Wei W, Xu X, Li H et al (2014) The SIRT2 polymorphism rs10410544 and risk of Alzheimer's disease: a metaanalysis. Neuromolecular Med 16:448-456. doi:10.1007/ s12017-014-8291-0

161. Piriz J, Muller A, Trejo JL, Torres-Aleman I (2011) IGF-I and the aging mammalian brain. Exp Gerontol 46:96-99. doi:10.1016/j.exger.2010.08.022

162. Trueba-Sáiz A, Cavada C, Fernandez AM et al (2013) Loss of serum IGF-I input to the brain as an early biomarker of disease onset in Alzheimer mice. Transl. Psychiatry 3:e330. doi:10.1038/tp.2013.102

163. Hu Y-K, Wang X, Li L et al (2013) MicroRNA-98 induces an Alzheimer's disease-like disturbance by targeting insulinlike growth factor 1. Neurosci Bull 29:745-751. doi:10.1007/ s12264-013-1348-5

164. Poirier R, Fernandez AM, Torres-Aleman I, Metzger F (2012) Early brain amyloidosis in APP/PS1 mice with serum insulinlike growth factor-I deficiency. Neurosci Lett 509:101-104. doi:10.1016/j.neulet.2011.12.048

165. Gontier G, George $\mathrm{C}$, Chaker $\mathrm{Z}$ et al (2015) Blocking IGF signaling in adult neurons alleviates Alzheimer's disease pathology through amyloid- $\beta$ clearance. J Neurosci 35:11500-11513. doi:10.1523/JNEUROSCI.0343-15.2015

166. de Bruijn RFAG, Janssen JAMJL, Brugts MP et al (2014) Insulin-like growth factor-I receptor stimulating activity is associated with dementia. J Alzheimers Dis 42:137-142. doi:10.3233/ JAD-140186

167. Bassil F, Fernagut P-O, Bezard E, Meissner WG (2014) Insulin, IGF-1 and GLP-1 signaling in neurodegenerative disorders: 
targets for disease modification? Prog Neurobiol 118:1-18. doi:10.1016/j.pneurobio.2014.02.005

168. Carro E, Trejo JL, Gomez-Isla T et al (2002) Serum insulin-like growth factor I regulates brain amyloid-beta levels. Nat Med 8:1390-1397. doi:10.1038/nm793

169. Perez FP, Bose D, Maloney B et al (2014) Late-onset Alzheimer's disease, heating up and foxed by several proteins: pathomolecular effects of the aging process. J Alzheimers Dis 40:117. doi:10.3233/JAD-131544

170. Akhter R, Sanphui P, Biswas SC (2014) The essential role of p53-up-regulated modulator of apoptosis (Puma) and its regulation by FoxO3a transcription factor in $\beta$-amyloid-induced neuron death. J Biol Chem 289:10812-10822. doi:10.1074/jbc. M113.519355

171. Manolopoulos KN, Klotz L-O, Korsten P et al (2010) Linking Alzheimer's disease to insulin resistance: the FoxO response to oxidative stress. Mol Psychiatry 15:1046-1052. doi:10.1038/ mp. 2010.17

172. Gómez Ravetti M, Rosso OA, Berretta R, Moscato P (2010) Uncovering molecular biomarkers that correlate cognitive decline with the changes of hippocampus' gene expression profiles in Alzheimer's disease. PLoS One. doi:10.1371/journal. pone. 0010153

173. Pino E, Amamoto R, Zheng L et al (2014) FOXO3 determines the accumulation of $\alpha$-synuclein and controls the fate of dopaminergic neurons in the substantia nigra. Hum Mol Genet 23:1435-1452. doi:10.1093/hmg/ddt530

174. Su B, Liu H, Wang X et al (2009) Ectopic localization of FOXO3a protein in Lewy bodies in Lewy body dementia and Parkinson's disease. Mol Neurodegener 4:32. doi:10.1186/1750-1326-4-32

175. Albani D, Polito L, Batelli S et al (2009) The SIRT1 activator resveratrol protects SK-N-BE cells from oxidative stress and against toxicity caused by alpha-synuclein or amyloid-beta (1-42) peptide. J Neurochem 110:1445-1456. doi:10.1111/j.1471-4159.2009.06228.x

176. Okawara M, Katsuki H, Kurimoto E et al (2007) Resveratrol protects dopaminergic neurons in midbrain slice culture from multiple insults. Biochem Pharmacol 73:550-560. doi:10.1016/j.bcp.2006.11.003

177. Chao J, Yu M-S, Ho Y-S et al (2008) Dietary oxyresveratrol prevents parkinsonian mimetic 6-hydroxydopamine neurotoxicity. Free Radic Biol Med 45:1019-1026. doi:10.1016/j. freeradbiomed.2008.07.002

178. Blanchet J, Longpré F, Bureau G et al (2008) Resveratrol, a red wine polyphenol, protects dopaminergic neurons in MPTPtreated mice. Prog Neuropsychopharmacol Biol Psychiatry 32:1243-1250. doi:10.1016/j.pnpbp.2008.03.024

179. Zhang A, Wang H, Qin X et al (2012) Genetic analysis of SIRT1 gene promoter in sporadic Parkinson's disease. Biochem Biophys Res Commun 422:693-696. doi:10.1016/j. bbrc.2012.05.059

180. Mudò G, Mäkelä J, Di Liberto V et al (2012) Transgenic expression and activation of PGC- $1 \alpha$ protect dopaminergic neurons in the MPTP mouse model of Parkinson's disease. Cell Mol Life Sci 69:1153-1165. doi:10.1007/s00018-011-0850-Z

181. Wu Y, Li X, Zhu JX et al (2011) Resveratrol-activated AMPK/ SIRT1/autophagy in cellular models of Parkinson's disease. Neurosignals 19:163-174. doi:10.1159/000328516

182. McLean PJ, Klucken J, Shin Y, Hyman BT (2004) Geldanamycin induces Hsp70 and prevents alpha-synuclein aggregation and toxicity in vitro. Biochem Biophys Res Commun 321:665669. doi:10.1016/j.bbrc.2004.07.021

183. Klucken J, Shin Y, Masliah E et al (2004) Hsp70 reduces alphasynuclein aggregation and toxicity. J Biol Chem 279:2549725502. doi:10.1074/jbc.M400255200
184. Westerheide SD, Anckar J, Stevens SM et al (2009) Stressinducible regulation of heat shock factor 1 by the deacetylase SIRT1. Science 323:1063-1066. doi:10.1126/science.1165946

185. Watanabe S, Ageta-Ishihara N, Nagatsu S et al (2014) SIRT1 overexpression ameliorates a mouse model of SOD1-linked amyotrophic lateral sclerosis via HSF1/HSP70i chaperone system. Mol Brain 7:62. doi:10.1186/s13041-014-0062-1

186. Chen X, Wales P, Quinti L et al (2015) The sirtuin-2 inhibitor AK7 is neuroprotective in models of Parkinson's disease but not amyotrophic lateral sclerosis and cerebral ischemia. PLoS ONE 10:e0116919. doi:10.1371/journal.pone.0116919

187. Guan Q, Wang M, Chen H et al (2016) Aging-related 1-methyl4-phenyl-1,2,3,6-tetrahydropyridine-induced neurochemial and behavioral deficits and redox dysfunction: improvement by AK-7. Exp Gerontol 82:19-29. doi:10.1016/j.exger.2016.05.011

188. Outeiro TF, Kontopoulos E, Altmann SM et al (2007) Sirtuin 2 inhibitors rescue alpha-synuclein-mediated toxicity in models of Parkinson's disease. Science 317:516-519. doi:10.1126/ science. 1143780

189. Hasegawa T, Baba T, Kobayashi M et al (2010) Role of TPPP/ p25 on $\alpha$-synuclein-mediated oligodendroglial degeneration and the protective effect of SIRT2 inhibition in a cellular model of multiple system atrophy. Neurochem Int 57:857-866. doi:10.1016/j.neuint.2010.09.002

190. Krey L, Lühder F, Kusch K et al (2015) Knockout of silent information regulator 2 (SIRT2) preserves neurological function after experimental stroke in mice. J Cereb Blood Flow Metab 35:2080-2088. doi:10.1038/jcbfm.2015.178

191. Narayan N, Lee IH, Borenstein R et al (2012) The NADdependent deacetylase SIRT2 is required for programmed necrosis. Nature 492:199-204. doi:10.1038/nature11700

192. Liu J, Wu X, Wang X et al (2013) Global gene expression profiling reveals functional importance of Sirt2 in endothelial cells under oxidative stress. Int J Mol Sci 14:5633-5649. doi:10.3390/ijms 14035633

193. Naia L, Rego AC (2015) Sirtuins: double players in Huntington's disease. Biochim Biophys Acta 1852:2183-2194. doi:10.1016/j.bbadis.2015.07.003

194. Kannike K, Sepp M, Zuccato C et al (2014) Forkhead transcription factor FOXO3a levels are increased in Huntington disease because of overactivated positive autofeedback loop. J Biol Chem 289:32845-32857. doi:10.1074/jbc.M114.612424

195. Jiang M, Wang J, Fu J et al (2012) Neuroprotective role of Sirt1 in mammalian models of Huntington's disease through activation of multiple Sirt1 targets. Nat Med 18:153-158. doi: $10.1038 / \mathrm{nm} .2558$

196. Duan W (2013) Targeting sirtuin-1 in Huntington's disease: rationale and current status. CNS Drugs 27:345-352. doi:10.1007/s40263-013-0055-0

197. Smith MR, Syed A, Lukacsovich T et al (2014) A potent and selective Sirtuin 1 inhibitor alleviates pathology in multiple animal and cell models of Huntington's disease. Hum Mol Genet 23:2995-3007. doi:10.1093/hmg/ddu010

198. Carafa V, Rotili D, Forgione M et al (2016) Sirtuin functions and modulation: from chemistry to the clinic. Clin Epigenetics. doi:10.1186/s13148-016-0224-3

199. Pontiki E, Hadjipavlou-Litina D (2012) Histone deacetylase inhibitors (HDACIs). Structure-activity relationships: history and new QSAR perspectives. Med Res Rev 32:1-165. doi: $10.1002 /$ med. 20200

200. Bedalov A, Gatbonton T, Irvine WP et al (2001) Identification of a small molecule inhibitor of Sir2p. Proc Natl Acad Sci USA 98:15113-15118. doi:10.1073/pnas.261574398

201. Napper AD, Hixon J, McDonagh T et al (2005) Discovery of indoles as potent and selective inhibitors of the deacetylase SIRT1. J Med Chem 48:8045-8054. doi:10.1021/jm050522v 
202. Orecchia A, Scarponi C, Di Felice F et al (2011) Sirtinol treatment reduces inflammation in human dermal microvascular endothelial cells. PLoS ONE 6:e24307. doi:10.1371/journal. pone. 0024307

203. Jung YJ, Lee JE, Lee AS et al (2012) SIRT1 overexpression decreases cisplatin-induced acetylation of NF- $\mathrm{kB}$ p65 subunit and cytotoxicity in renal proximal tubule cells. Biochem Biophys Res Commun 419:206-210. doi:10.1016/j. bbrc.2012.01.148

204. Xu Y, Nie L, Yin Y-G et al (2012) Resveratrol protects against hyperglycemia-induced oxidative damage to mitochondria by activating SIRT1 in rat mesangial cells. Toxicol Appl Pharmacol 259:395-401. doi:10.1016/j.taap.2011.09.028

205. Luthi-Carter R, Taylor DM, Pallos J et al (2010) SIRT2 inhibition achieves neuroprotection by decreasing sterol biosynthesis. Proc Natl Acad Sci USA 107:7927-7932. doi:10.1073/ pnas. 1002924107

206. Nie H, Chen H, Han J et al (2011) Silencing of SIRT2 induces cell death and a decrease in the intracellular ATP level of PC12 cells. Int J Physiol Pathophysiol Pharmacol 3:65-70

207. Villalba JM, Alcaín FJ (2012) Sirtuin activators and inhibitors. Biofactors 38:349-359. doi:10.1002/biof.1032

208. Neugebauer RC, Uchiechowska U, Meier R et al (2008) Structure-activity studies on splitomicin derivatives as sirtuin inhibitors and computational prediction of binding mode. J Med Chem 51:1203-1213. doi:10.1021/jm700972e

209. Wang TTY, Schoene NW, Kim E-K, Kim YS (2013) Pleiotropic effects of the sirtuin inhibitor sirtinol involves concentrationdependent modulation of multiple nuclear receptor-mediated pathways in androgen-responsive prostate cancer cell LNCaP. Mol Carcinog 52:676-685. doi:10.1002/mc.21906

210. Baur JA, Pearson KJ, Price NL et al (2006) Resveratrol improves health and survival of mice on a high-calorie diet. Nature 444:337-342. doi:10.1038/nature05354
211. Chung S, Yao H, Caito S et al (2010) Regulation of SIRT1 in cellular functions: role of polyphenols. Arch Biochem Biophys 501:79-90. doi:10.1016/j.abb.2010.05.003

212. Aquilano K, Vigilanza P, Baldelli S et al (2010) Peroxisome Proliferator-activated Receptor $\gamma$ Co-activator $1 \alpha$ (PGC-1 $\alpha)$ and Sirtuin 1 (SIRT1) Reside in Mitochondria. J Biol Chem 285:21590-21599. doi:10.1074/jbc.M109.070169

213. Resveratrol for Alzheimer's Disease-Tabular View-ClinicalTrials.gov. https://clinicaltrials.gov/ct2/show/record/NCT01504 854 ?term $=$ sirtuin\&rank=14. Accessed 3 Feb 2016

214. Influence of Caloric Restriction and Resveratrol in the Sirtuin System in Women and Men Aged 55-65 Years-Full Text View-ClinicalTrials.gov. https://clinicaltrials.gov/ct2/show/ NCT01668836?term $=$ sirtuin\&rank=1\&submit_fld_opt $=$. Accessed 3 Feb 2016

215. Resveratrol to Enhance Vitality and Vigor in Elders-Full Text View-ClinicalTrials.gov. https://clinicaltrials.gov/ct2/show/ NCT02123121?term =sirtuin\&rank=18\&submit_fld_opt $=$. Accessed 3 Feb 2016

216. Reresveratrol Administered to Healthy Male Subjects-Full Text View-ClinicalTrials.gov. https://clinicaltrials.gov/ct2/ show/study/NCT01768507?term $=$ sirtuin\&rank $=5$. Accessed 3 Feb 2016

217. Jiang M, Zheng J, Peng Q et al (2014) Sirtuin 1 activator SRT2104 protects Huntington's disease mice. Ann Clin Transl Neurol 1:1047-1052. doi:10.1002/acn3.135

218. Venkatasubramanian S, Noh RM, Daga S et al (2013) Cardiovascular effects of a novel SIRT1 activator, SRT2104, in otherwise healthy cigarette smokers. J Am Heart Assoc 2:e000042. doi:10.1161/JAHA.113.000042

219. D'Onofrio N, Vitiello M, Casale R et al (2015) Sirtuins in vascular diseases: emerging roles and therapeutic potential. Biochim Biophys Acta 1852:1311-1322. doi:10.1016/j. bbadis.2015.03.001 